\title{
O CURRÍCULO NA E DA ENFERMAGEM: POR ONDE COMEÇAR E RECOMEÇAR
}

\author{
Dulce Maia Silva Vendrúscolo* \\ Maria Cecília Manzolli**
}

VENDRÚSCOLO, D.M.S.; MANZOLLI, M.C. O currículo na e da enfermagem: por onde começar e recomeçar. Rev. latino-am. Enfermagem., Ribeirão Preto, v.4, n. 1, p. 55-70, janeiro 1996.

Este estudo apóia-se na premissa de que toda prática educacional se faz baseada em pressupostos de natureza filosófica e pedagógica, representando o currículo, a visão de mundo percebida pela escola e seus professores. A questão orientadora desta investigação assim se coloca: Qual a percepção do professor sobre as concepções curriculares norteadoras do currículo de graduação de enfermagem? Participaram da pesquisa 36 professores de 9 escolas paulistas de enfermagem que responderam à entrevista formulada a partir da técnica do Diferencial Semântico. As concepções-educacionais, tradicionalista, cognitiva, comportamentalista, de autorealização e de reconstrução social, orientaram esta análise. Os resultados da pesquisa expressaram as preferências dos sujeitos para posturas educacionais de caráter humanístico e social, demonstrando haver, entretanto, a orientação ora para postura mais renovadoras, ora para mais tradicionais, caracterizando não haver uma concepção predominante na orientação do currículo. A realidade curricular da enfermagem demonstra a existência de um plurarismo de posturas filosóficas e pedagógicas na orientação do ensino de graduação, sendo estas opções, muitas vezes, resultantes das aspirações e dos ideais do próprio professor atribuídos ao processo educacional vigente na enfermagem.

UNITERMOS: currículo em enfermagem, educação em enfermagem

*Professor Assistente Doutor do Departamento de Enfermagem Materno-Infantil e Saúde Pública da Escola de Enfermagem de Ribeirão Preto da Universidade de São Paulo.

**Professor Associado do Departamento de Enfermagem Psiquiátrica e Ciências Humanas da Escola de Enfermagem de Ribeirão Preto da Universidade de São Paulo. 


\section{INTRODUÇÃO}

A literatura brasileira de enfermagem tem enfatizado nos últimos anos a questão do currículo, mas poucos são os trabalhos que fundamentam suas críticas nas diferentes concepções filosóficas e pedagógicas existentes.

O que significa currículo? Numa abordagem psico-pedagógica o significado do mesmo passa pela proposta de um conteúdo lógico, seqüencial, contínuo, pautado por objetivos educacionais previamente definidos, vivenciados através das experiências de aprendizagem organizadas pelo professor. Esta modalidade de currículo se identifica com uma visão conservadora onde prevalece o enfoque instrucional e metodológico. $\mathrm{Na}$ perspectiva deste enfoque tecnicista o currículo tem como pressuposto a previsão, a pré -determinação e o planejamento, buscando atingir requisitos científicos de rigor, exatidão objetividade (SILVA, 1990).

Mais recentemente a teoria curricular e a educacional apontam a necessidade de se compreender o currículo além de suas dimensões técnico-pedagógicas, entendendo-o como um ato de renovação e compromisso social. Esta modalidade incorpora a noção de um currículo-formação voltada para a consciência crítica, emancipação e humanização do homem, assumindo questões de natureza ética, política, social e não apensas as de ordem ténica-instrumental (DOMINGUES, 1986; SILVA, 1990).

Esta linha de orientação teórica se opõe ao fato de considerar o currículo como um ato isolado de um compromisso da escola para com seus alunos e a comunidade; coloca a possibilidade de entendê-lo como um ato social, um compromisso para com uma determinada comunidade ocupacional, conduzido por diferentes postulados, prática e valores sociais que irão mediar a formação e desempenho profissional.

As considerações deste grupo de autores evidenciam diferentes abordagens do currículo traduzidas em múltiplas concepções que, muitas vezes, se contrapõem. Todas essas concepções, não importando suas estruturas particulares, se compõem de certos elementos valorativos que direcionam as decisões sobre procedimentos e conteúdos curriculares.

Segundo YAMAMOTO \& ROMEU (1983) o professor irá influenciar o processo educacional de acordo com sua ótica particular, condicionada pela maneira como ele vê e sente o mundo. A ação educativa será traduzida ora por posturas sociais ou de renovação.

No entender de MANZOLLI (1985), a "visão que uma escola tem do homem e do mundo lhe permite assumir uma posição predominantemente tecnicista ou humanista. A tendência a uma posição mais tecnicista terá seu currículo voltado para a supremacia da técnica; a posição mais humanística terá o homem como centro e o aluno preparado para responder ao conjunto de situações com que se defrontar. Serão as ciências humanas e sociais que thes darão esse embasamento". (p.1) 
Estas tendências no currículo da Enfermagem apreendem diferentes formas de se conceber o mundo, a sociedade, o homem, o setor saúde, os métodos e processos educacionais, resultando, portanto, em diferentes formas de se perceber e vivenciar o currículo e diferentes formas de agir do profissional enfermeiro.

Diante desse quadro inicial, prosseguiremos enveredando-nos nas abordagens filosóficas e pedagógicas que vem orientando o currículo de enfermagem, muitas vezes sem que tomássemos conhecimento do referencial em que se baseia.

\section{CURRÍCULO - ABORDAGENS FILOSÓFICAS-PEDAGÓGICAS}

Tratando, pois esta investigação de apresentar subsídios para compreensão das diferentes e concepções curriculares e abordagens filosóficas e pedagógicas no currículo da enfermagem, vimos que esta tarefa não é simples como parece a primeira vista. Buscamos, primeiramente, na literatura educacional um modelo que pudesse orientar o curso desta análise constatando que diversos autores lançam mão de modelos ou paradigmas curriculares que emprestam diferentes formas de interpretação ao currículo.

Citamos aqui os trabalhos de EISNER \& VALLANCE (1974) desenvolvidos nos Estados Unidos nos anos 70, que repercutiram na teoria educacional, vindo a influenciar também os educadores brasileiros em vários campos da educação, como o demonstram os trabalhos de YAMAMOTO \& ROMEU (1983); MOREIRA \& AXT (1986); MIZUKAMI (1986); GUIMARÃES (1987). As concepções curriculares identificadas por aqueles autores não esgotam, necessariamente, as diferentes posições teóricas que podem ser caracterizadas ou identificadas neste campo; constituem, entretanto, uma síntese das tendências conceituais distintas que emergiram na literatura, no campo da teoria educacional e curricular.

O citado modelo de EISNER \& VALLANCE (1974) apresenta cinco concepções curriculares - o currículo como racionalismo acadêmico; como desenvolvimento do processo cognitivo; como tecnologia, como auto-realização e como reconstrução social.

Apresentaremos a seguir os principais enfoques de caráter filosófico e pedagógico que orientam cada uma dessas concepções.

O currículo como racionalização acadêmica: é o currículo tradicional cuja concepção incorpora os aspectos filosóficos que norteiam as correntes tradicionais da educação. O currículo é visto como conteúdos organizados e transmitidos aos educandos, sendo o professor o elemento de comunicação e transmissão.

Esta concepção é marcada pela visão essencialista do homem, em que é considerado como inserido num mundo que irá conhecer através das informações 
consideradas úteis, O mundo é externo ao indivíduo, vindo a ser dominado mediante o conhecimento adquirido por processo cumulativo, decorrente de uma educação formal.

São características deste modelo: a escola como local de apropriação do conhecimento por meio da transmissão de conteúdos e confrontos com modelos e demonstrações, sendo a ênfase colocada na intervenção do professor, o currículo com o conjunto de conhecimentos relevantes à profissão, transmitidos pelo professor; as matérias constituem um método lógico e eficaz para organizar conhecimentos novos. O método expositivo é utilizado como atividade didática principal na transmissão de conceitos e informações; o professor detém o controle decisório da ação educativa - o aluno é um ser passivo nesse processo; a avaliação é realizada por meio de provas e exames que visam à reprodução do conteúdo comunicado (KNELLER, 1971; MIZUKAMI, 1986; YAMAMOTO \& ROMEU, 1983).

Nesta concepção permanece uma conotação de neutralidade, tanto em nível do processo educacional como do pedagógico-social.

o currículo como desenvolvimento do processo cognitivo: este enfoque centraliza-se no desenvolvimento de operações intelectuais e no como ensinar, deixando de enfatizar o conteúdo instrucional. O objetivo do currículo é o desenvolvimento de processos intelectuais e habilidades cognitivas que possam ser aplicados ao processo ensino-aprendizagem.

Esta concepção decorre da influência da corrente progressiva revelada através das idéias de DEWEY, filósofo e educador norte-americano, cujos princípios fortaleceram a educação como um processo social. O movimento progressista consistiu na aplicação do pragmatismo e da filosofia progressista, assim denominada por caracterizar um movimento de transformação social, onde os ideais de democracia e cooperação eram enfatizados (DEWEY, 1978; KNELLER, 1971).

A proposta de educação segundo esta concepção é ensinar o educando a pensar efetivamente, analisar, criticar, escolher entre alternativas e arriscar soluções à base da análise da relação; o currículo visa a desenvolver no aluno habilidades cognitivas buscando a promoção da autonomia intelectual do educando; a metodologia de ensino parte da situação problematizadora e da experimentação, levando o aluno a desenvolver sua capacidade de resolução de problemas; o professor é conselheiro e guia; o estudante é tratado como um ser ativo e independente; o interesse, a atividade, a participação e a assiduidade são observadas no processo de avaliação do educando (SPERB, 1975; TABA, 1974).

O currículo como tecnologia - abordagem comportamentalista: esta concepção ressalta o processo de como ensinar e como aprender. A tecnologia educacional é o meio através do qual o conhecimento é comunicado e a aprendizagem é facilitada, ocupando o professor e o aluno posições secundárias neste processo (SPERB, 1975).

Esta orientação busca a eficiência instrumental apoiada em diferentes 
propostas pedagógicas como o enfoque sistêmico, o micro-ensino, o tele-ensino, a instrução programada. Dentre os pesquisadores que se dedicaram a esta linha de estudo, SKINNER (1972) destaca-se como representante desta abordagem comportamentalista, com grande repercussão no Brasil na década de 60 .

O planejamento educacional decorrente das políticas que vigoravam no país após os anos sessenta durante o período militar, radicaliza este modelo, tomando-o na educação e vendo esta como meio de controle social e político. O modelo tecnicista se torna absoluto, sobretudo, com a vigência da lei 5692/71, com a Reforma do Ensino de Primeiro e Segundo Graus, valorizando a formação técnico-profissional, privilegiando-se os métodos, as técnicas de ensino, como forma de racionalizar a tomada de decisões no processo educacional. (FREITAG, 1979; SAVIANI, 1984).

São características desse modelo; a educação entendida como um processo de transmissão cultural; o desenvolvimento da aprendizagem partindo de experiências curriculares planejadas, dirigidas à consecução dos objetivos ou comportamentos finais; a experiência de ensino planejada através da especificação dos objetivos, meios, metodologia e da avaliação; a programação do ensino permitindo a individualização e o respeito ao ritmo do aluno.

O currículo como auto-realização: esta orientação baseada no conteúdo, apresentando-se saturada de valores, vendo no currículo a função de prover experiências pessoalmente realizadoras para cada aprendiz. A educação segundo esta abordagem constitui um processo que deve prover meios para a libertação e desenvolvimento pessoal, estando centrada no aluno e orientada para autonomia e crescimento pessoal (ROGERS, 1972; BICUDO, 1983).

Esta proposta encerra as idéias da educação humanística moderna, cujas principais correntes filosóficas são o existencialismo e a fenomenologia. Incorpora, dessa forma, a análise dos processos pessoais de auto-realização baseando-se numa orientação fenomenológica existencial, onde o ser que aprende é visto como pessoa. Os principais conceitos advindos dessa concepção se referem à educação como processo que capacita o educando a se desenvolver como pessoa através da auto-descoberta, enfatizando sua auto-realização; o currículo cria condições que facilitam a aprendizagem, enfatizando a pessoa do aluno e sua auto-realização; o método de ensino não diretivo, o diálogo, a problematização e a relação interpessoal colocam o aluno como centro do processo educativo; o professor é o facilitador da aprendizagem - o aluno é um ser que auto desenvolve.

O currículo como reconstrução social: esta concepção parte de uma abordagem crítica e revolucionária cujo conjunto de idéia geradas no campo político social tornamse um corpo de conhecimento importante na área educacional, na medida em que postulam que a educação deve ser compreendida a partir de seus determinantes sociais. Esta abordagem é uma característica da sociedade ocidental que atribui à 
escola a função de servir como elemento de mudança social, colocando a educação e o currículo em relação com as questões sociais da atualidade. O currículo sobre o enfoque crítico revolucionário transforma-se num ato político que objetiva a emancipação das camadas populares; ele é visto como meio através do qual os estudantes aprendem a lidar com questões sociais (EISNER \& VALLANCE, 1974; DOMINGUES, 1986; MIZUKAMI, 1986).

A educação aqui está voltada para a transformação de ordem social, sendo a escola o agente de mudança e o homem o sujeito da educação; o currículo visa à formação do homem no contexto social; a metodologia de ensino estimula debates, a análise dos problemas, dos movimentos sociais e troca de experiências; o professor e o aluno devem estar engajados numa prática transformadora; a avaliação é entendida como processo participativo e coletivo.

Diante do quadro de referência teórica aqui exposto, fundamentamos a posição que adotamos neste trabalho, levando a entender o currículo não como um ato neutro, isolado do contexto onde a escola e o profissional se inserem, mas como um processo em evolução constante, um compromisso para com a sociedade a qual se destina. A partir desta posição percebemos que o currículo não se restringe somente às tarefas de delineamento do conteúdo instrucional buscando 0 desenvolvimento de habilidades cognitivas, afetivas e psicomotoras. Este, passa a significar a expressão máxima do trabalho interdisciplinar desenvolvido pela escola, pelos professores e alunos nas atividades de ensino, assistência, pesquisa, conduzindo à formação de um profissional competente e consciente de seu papel social.

O referencial teórico que orienta esta análise aponta, ainda, para o fato de que toda a prática educacional se faz baseada em pressupostos de natureza filosófica e pedagógica e que a relação ensino-aprendizagem não é neutra. Interessa-nos nesse processo a figura do professor envolvido com o ensino d e graduação em enfermagem, uma vez que este imprime a sua prática pedagógica diferentes abordagens ao processo ensino-aprendizagem, segundo a sua concepção de mundo, de homem, de educação, do aluno, da saúde e da Enfermagem.

Resulta desta reflexão-teórica a noção de que:

a prática educacional

a relação ensino aprendizagem

a ação educativa
Se desenvolve pautada por pressupostos de natureza filosófica e pedagógica;

não é neutra, pois expressa uma série de valores referentes a seus objetivos, conteúdos, métodos e formas de avaliação;

relativa a escola e ao professor imprime diferentes abordagens ao processo educacional. 
A questão orientadora. Visto que a prática pedagógica do professor sugere diferentes abordagens no currículo, a questão orientadora de nosso estudo assim se apresenta:

\section{- que a percepção o professor tem das concepções curriculares norteadas do currículo de graduação em enfermagem?}

A partir da questão orientadora fomos estudar a realidade curricular da enfermagem.

\section{METODOLOGIA}

A metodologia do estudo curricular - Participaram desta análise 36 sujeito, sendo 27 professores e 9 coordenadores ou diretores de curso de enfermagem de nove escolas paulistas de Enfermagem - 3 públicas e 6 particulares de natureza laica ou leiga e religiosa.

O material utilizado na presente pesquisa inclui instrumento elaborado a partir de uma instrução oral e escrita que serviu de roteiro à entrevista realizada com os 36 sujeitos. A instrução oral teve por finalidade esclarecer os objetivos da pesquisa, além de orientar quanto a forma de conduzir o preenchimento da instrução escrita. As entrevistas foram realizadas pelo próprio pesquisador.

De posse do modelo teórico apresentado por EISNER \& VALLANCE (1974), elaboramos o roteiro par a entrevista que teve por base duas categorias de conceitos:

- aqueles decorrentes das abordagens curriculares ressaltadas: tradicionalista, cognitivista, comportamentalista, de auto-realização, de reconstrução social;

- os conceitos advindos do processo ensino-aprendizagem: educação, currículo, processo de ensino-aprendizagem, relacionamento professor e aluno e avaliação.

Por lidarmos com conceitos de natureza filosófica e pedagógica que podem imprimir certo grau de subjetividade às respostas emitidas pelo sujeito, optamos pela elaboração do instrumento a partir da técnica do Diferencial Semântico (DS). Esta técnica é utilizada na área das ciências humanas para medir o significado afetivo e ou interpretar atitudes e valores sobre um determinado conceito ou grupo de conceitos. Possibilita registrar e comparar o significado de um ou vários conceitos, para um ou vários indivíduos, mediante um conjunto de escalas (OSGOOD, 1957; PEREIRA, 1986).

Os estudos nesta linha de pesquisa levaram à proposição de uma estrutura de espaços semânticos, definida pelas dimensões valorativas de potência e atividade caracterizada respectivamente, por adjetivos quantificadores como bom-mau; bonito-feio; fraco-forte. Estas dimensões possibilitaram a construção 
de uma escala semântica a partir de escalas bipolares definidas por um par de adjetivos polares, opostos em seus significados. Cada intervalo condiz com um valor numérico representado por:

\begin{tabular}{|c|c|c|c|c|c|c|}
\hline+3 & +2 & +1 & 0 & -1 & -2 & -3 \\
\hline 1 & 2 & 3 & 4 & 5 & 6 & 7 \\
\hline
\end{tabular}

Com base nas considerações acima, utilizamos o DS na construção do instrumento para avaliar a percepção do professor sobre as diferenças concepções norteadoras do currículo de graduação em enfermagem.

Os conceitos sobre Educação, Currículo, Metodologia de Ensino, Relacionamento Professor-Aluno e Avaliação, sintetizados a partir do referencial teórico de EISNER \& VALLANCE, (1974) formam uma escala graduada contendo em seus pólos os quantificadores "extremamente importante" e "pouco importante", segundo modelo adaptado da técnica do DS. Construímos cinco quadros, representando cada um deles uma das concepções curriculares do modelo estudado. A tarefa do sujeito da pesquisa, uma vez apresentando-Ihe cada quadro, era a de se posicionar face a cada conceito educacional, valendose da escala graduada. A opção do sujeito por um ponto da escala definia a posição e a direção no continuo escalar, em relação, aos quantificadores "extremamente importante", "pouco importante", obtendo-se assim a percepção dos sujeitos frente a cada uma das concepções analisadas.

\section{ANÁLISE E COMENTÁRIOS}

A realidade curricular observada. A escala do DS formulada a partir dos conceitos educacionais conduziu o julgamento perceptivo dos sujeitos permitindo traçar o perfil das concepções analisadas, a partir da avaliação dos sujeitos em cada um dos conceitos, representada pelos pontos lotados nas escalas.

A Figura 1 apresenta o perfil das concepções curriculares traçadas a partir do julgamento perceptivo dos 36 sujeitos, sendo 9 diretores ou coordenadores do curso, 27 professores. Em linhas gerais este perfil traduz a percepção destes, quanto a diferentes concepções que norteiam o processo de ensino na enfermagem. 


\section{FIGURA 1 - CONCEPÇÕES CURRICULARES ORIENTADORAS DO CURRÍCULO DE GRADUAÇÃO, RESPOSTAS DE DIRETORES E PROFESSORES DE ESCOLAS PAULISTAS DE ENFERMAGEM}

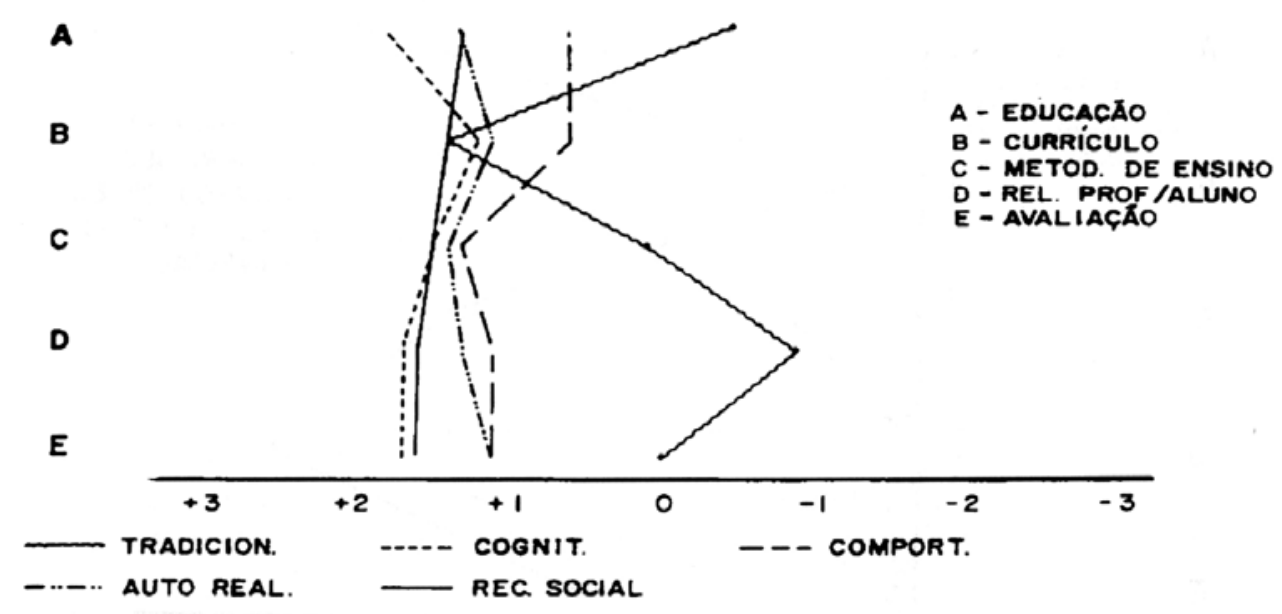

Da representação gráfica da Figura 1 apreende-se que as concepções curriculares de orientação cognitivista, de auto-realização e de reconstrução social foram julgadas positivamente pelos sujeitos, permitindo traçar um perfil quase linear no pólo (+2 e +1) na escala do DS.

A concepção comportamentalista, embora julgada também no pólo positivo da escala, tende a se distanciar das demais concepções na avaliação atribuída aos conceitos de educação e de currículo, aproximando-se do pólo de neutralidade da escala. A concepção tradicionalista se coloca, preferencialmente, no pólo neutro da escala, significando uma certa indecisão desses sujeitos em aceitar estes princípios educacionais como norteadores do currículo de graduação em enfermagem, embora revelando a tendência para aceitar uma postura mais tradicionalista na orientação do currículo.

Da análise conjunta desses dados percebemos, contudo, que os enfoques curriculares voltados para atitudes de mudanças e inovação, predominam no julgamento perceptivo dos sujeitos, reafirmando tendências para posturas mais renovadoras-humanistas e sociais - que tendem a considerar as dimensões pessoais e sociais do processo educacional. Existe ainda, tendência a rejeitar posturas mais tradicionalistas e conservadoras, quando se tem a avaliação. Este julgamento, revelando atitudes conservadoras e renovadoras na orientação do desenvolvimento curricular, evidencia um pluralismo na interpretação desses conceitos.

Chamamos a atenção para o fato de os sujeitos desta análise pertencerem a instituições diferentes, de natureza pública e particular-laicas e religiosas. Vale lembrar que 9 (nove) destes sujeitos são diretores de escolas ou coodenadoras de curso de enfermagem, exercendo atividades de direção e chefia, não propriamente a de ensino de graduação.

Buscando destacar o julgamento perceptivo dos diretores ou coordenadores de cursos, apresentamos a Figura 2. 


\section{FIGURA 2 - CONCEPÇÕES CURRICULARES ORIENTADORAS DO CURRÍCULO DE GRADUAÇÃO, RESPOSTAS DOS DIRETORES DE ESCOLAS PAULISTAS DE ENFERMAGEM}

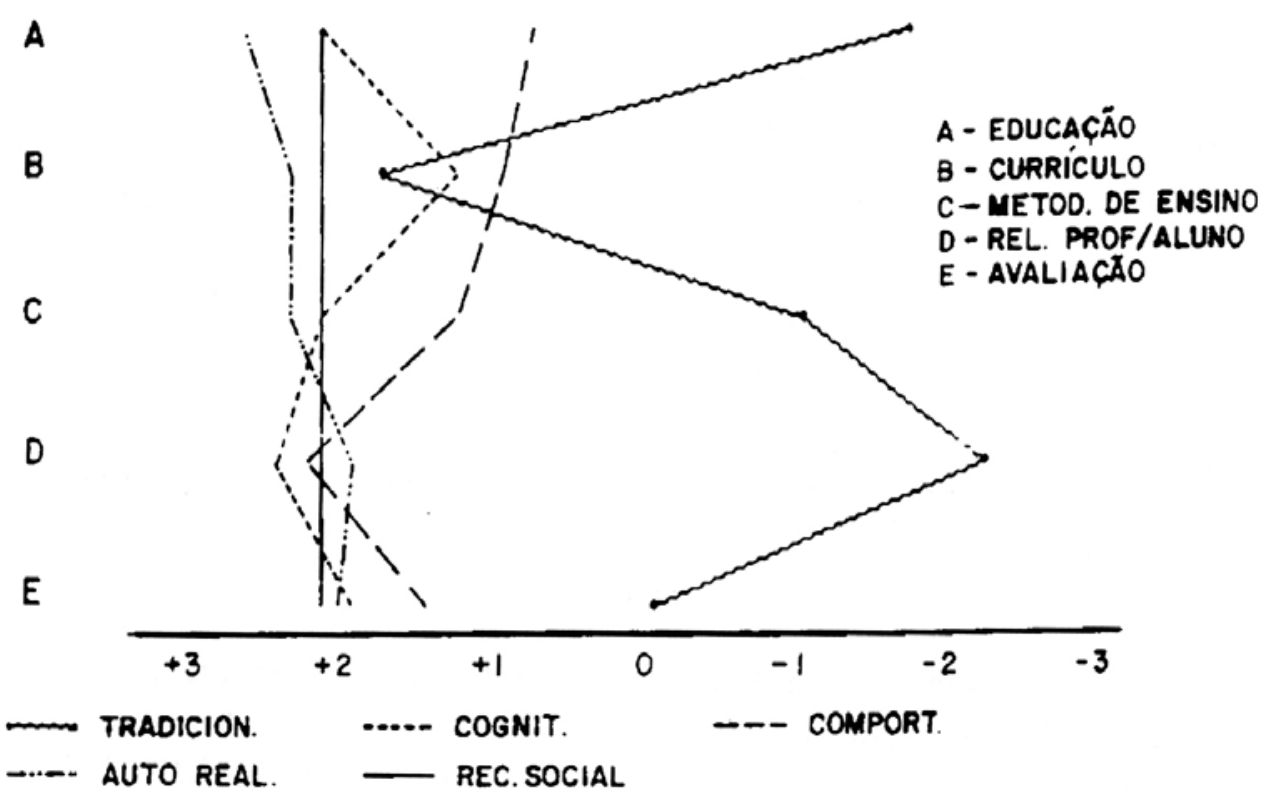

Deve-se considerar que a visão de currículo trazida no julgamento perceptivo destes sujeitos não pode estar dissociada da prática pedagógica advinda das experiências educacionais proporcionadas pelas escolas públicas e as pariculares-laicas e religiosas. Estes sujeitos ocupam, ainda, posição de destaque no encaminhamento de decisões normativas e funcionais que orientam as diretrizes assumidas pelas escolas na condução do currículo e do trabalho do professor.

Pela Figura 2 as preferências destes sujeitos se mantém pelas concepções curriculares referidas na análise anterior, colocando-se no pólo positivo da escala representada pelo intervalo $+3+2$. Há uma tendência em considerar mais aceitável a orientação do currículo como enfoque voltado para a reconstrução social, tendendo a manter um sentido de neutralidade e de negação ao currículo tradicionalista.

A valorização de posturas mais renovadoras na orientação do currículo de enfermagem parece representar, mais do que o julgamento dos sujeitos acerca destas orientações, as expectativas pessoais de cada um deles, lavando-nos a crer na ausência de um processo de reflexão a respeito da realidade educacional no ensino da enfermagem, nas redes públicas e nas particulares.

As Figuras 3, 4 e 5 trazem o julgamento perceptivo dos professores das escolas públicas e das particulares-laicas e religiosas. 


\section{FIGURA 3 - CONCEPÇÕES CURRICULARES ORIENTADORAS DO CURRÍCULO DE GRADUAÇÃO, RESPOSTAS DOS PROFESSORES DE ESCOLAS PAULISTAS DE ENFERMAGEM - PÚBLICAS}

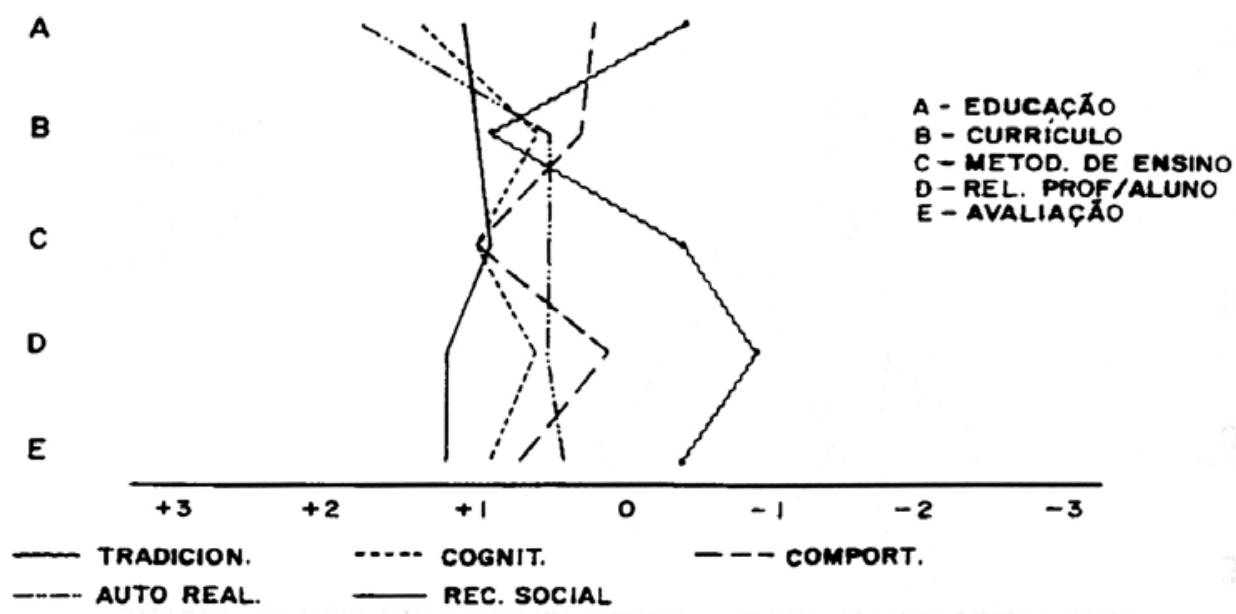

Pela Figura 3 no julgamento perceptivo dos 14 professores das escolas públicas percebe-se que a avaliação dos conceitos permanece no intervalo escalar +2 e 0 , afastando-se do pólo positivo e reforçando o caráter de neutralidade atribuído a esses conceitos. Esta avaliação pode estar relacionada a uma certa reserva desses professores em aceitar a existência de posturas mais renovadoras no ensino da enfermagem e a possibilidade de o currículo se pautar em posturas mais tradicionais. Este comportamento favorece uma visão mais crítica acerca dos processos educacionais na enfermagem.

\section{FIGURA 4 - CONCEPÇÕES CURRICULARES ORIENTADORAS DO CURRÍCULO DE GRADUAÇÃO, RESPOSTAS DOS PROFESSORES DE ESCOLAS PAULISTAS DE ENFERMAGEM - PARTICULARES RELIGIOSAS}

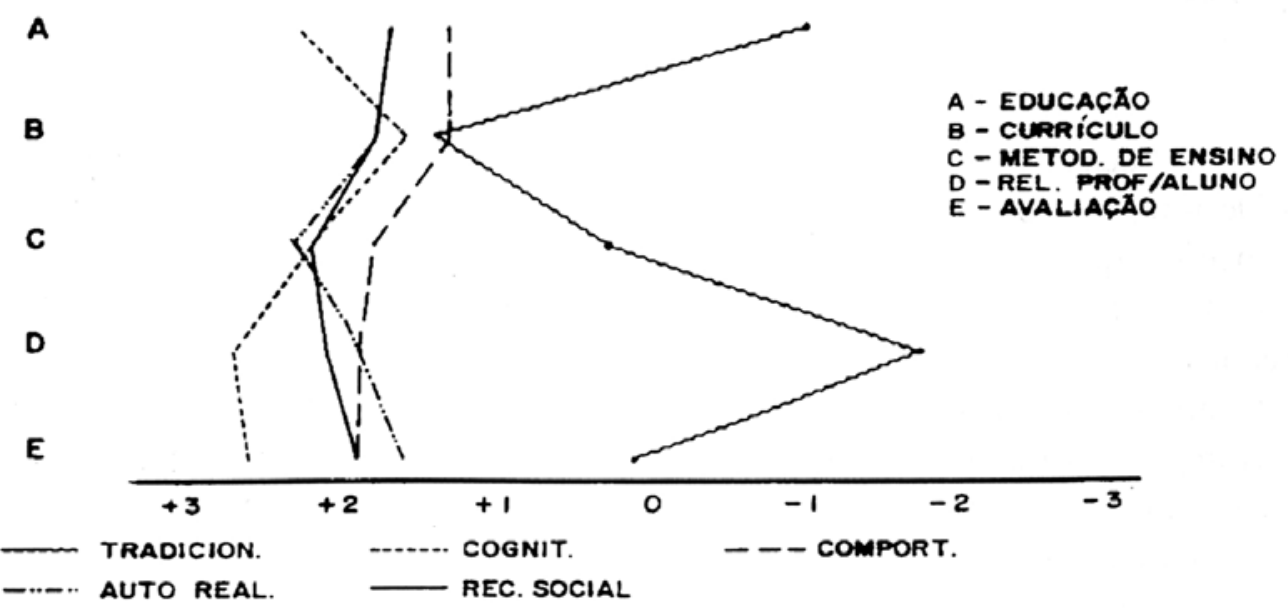


FIGURA 5 - CONCEPÇÕES CURRICULARES ORIENTADORAS DO

CURRÍCULO DE GRADUAÇÃO, RESPOSTAS DOS PROFESSORES

DE ESCOLAS PAULISTAS DE ENFERMAGEM - PARTICULARES

\section{LAICAS}

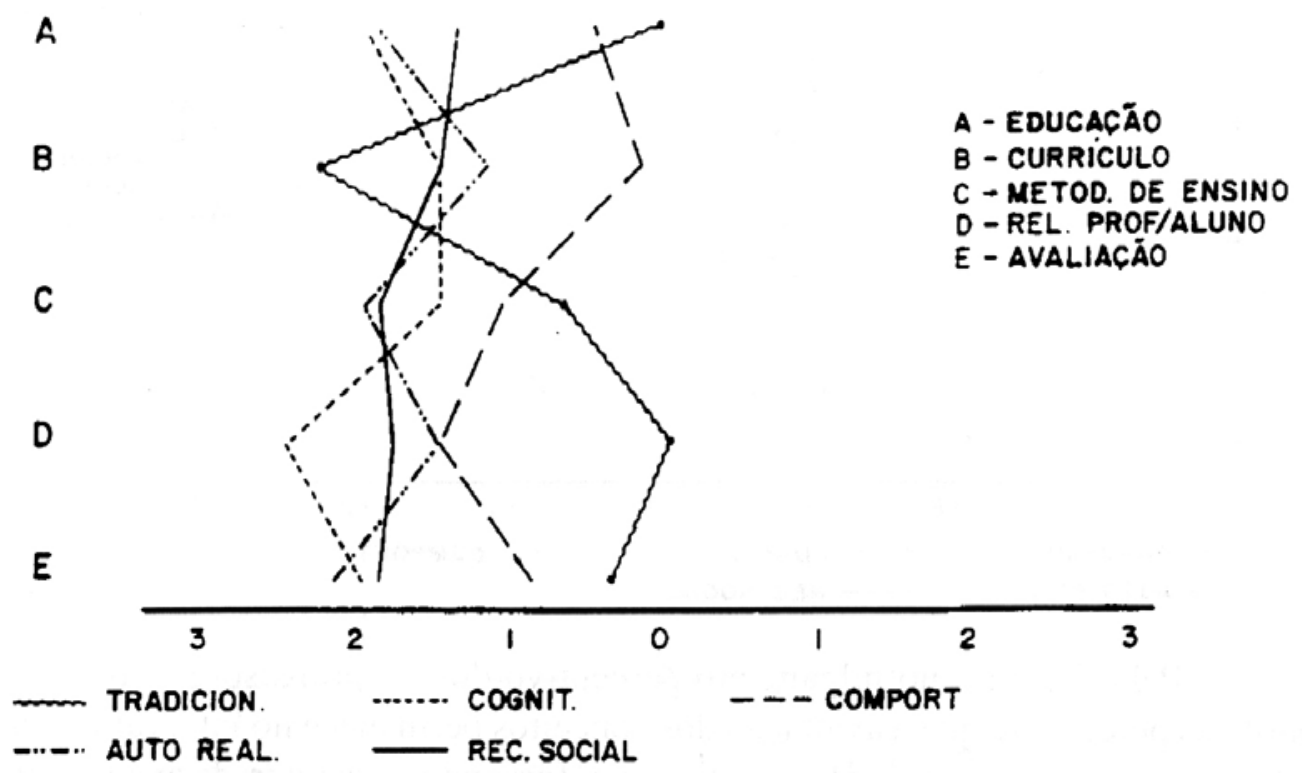

Por outro lado, a avaliação dos professores das escolas particulares religiosas e laicas, apresentadas na Figura 4 e 5, tende a revelar a aceitação bastante positiva de posturas mais renovadoras, tanto quanto de posturas mais tradicionais, colocando estes valores no pólo mais positivo da escala. Esta valorização é atribuída, sobretudo, à orientação do currículo sob abordagem cognitivista e de auto-realização.

\section{CONCLUSÃO}

Face aos dados até aqui analisados foi possível algumas considerações:

- De um modo geral constatamos o julgamento predominante dos sujeitos por conceitos que orientam o currículo para a inovação e mudança; esta percepção aponta para enfoques curriculares de orientação acentuadamente cognitivista, de reconstrução social, de auto-realização.

- O julgamento dos sujeitos parece expressar pouca preferência aos conceitos puramente comportamentalista tradicionalista, caracterizando postura de neutralidade à aceitação destas orientações, não demonstrando, entretanto, uma atitude de franca negação destes conceitos.

- A dispersão de julgamentos na escala do DS se explica pelo jogo dialético 
estabilidade-mudança, que possibilita integrar ao processo educacional posturas ora renovadoras, ora mais conservadoras, através da valorização de concepções tradicionais, humanistas e sociais.

- O julgamento perceptivo dos sujeitos assinalados nestas observações é compatível com dados da literatura que apontam a preferência de professores e alunos para orientações curriculares mais humanistas-renovadoras e sociais. Estes mesmos estudos revelam, no entanto, que na prática do professor predominam as posturas mais tradicionais e conservadoras.

- A existência de um pluralismo de orientações filosóficas e pedagógicas na interpretação do processo ensino-aprendizado, não permite detectar opções predominantes no currículo de enfermagem, mesmo que estas opções sejam resultantes das aspirações dos sujeitos e do ideal atribuído ao processo educacional da enfermagem.

\section{CONSIDERAÇÕES FINAIS}

Projetando a realidade curricular. Os rumos de uma reorientação para a política de saúde a partir dos anos 80 e 90 amparados pelos princípios de uma nova política nacional de saúde e de formação de recursos humanos nesta área apontam para a necessidade de revermos as questões as que norteiam a prática profissional e a orientação do ensino da enfermagem (ALMEIDA et al. 1986; PINTO, 1986). O currículo mínimo do curso de graduação em enfermagem, aprovado pelo Parecer CFE $n^{\circ}$ 314/94, homologado pela Portaria $n^{\circ} 1.721$, de 15 de dezembro de 1994 do Ministério da Educação e do Desporto, tem como referencial uma visão crítica das condições de vida, do perfil epidemológico da população, das diretrizes das políticas de saúde voltada para a descentralização e regionalização dos serviços e a municipalização da saúde.

Estas diretrizes falam a favor de posturas mais renovadoras que, no plano educacional, possam consolidar a formação de um profissional mais crítico e consciente de seu papel social. Impõe-se desta forma, novas diretrizes para formação do enfermeiro e prioridades para o ensino e a organização de experiências de aprendizagem, cabendo às escolas e aos seus professores a revisão e a reflexão sobre as posições pedagógicas que orientam o currículo nas escolas de enfermagem.

Dessa forma, vislumbramos para o ano 2000 uma direção científica e filosófica não tão fracionária como a que vem acontecendo atualmente. É necessário que pensemos de modo mais abrangente a educação e sua própria ciência. A unificação de modelos num paradigma mais amplo ajudará a entender o dialetismo nas respostas aqui encontradas. A superposição de conceitos com nomes diversos, 
a política de adeptos na área educacional vão aos poucos ceder lugar a uma unificação da educação que englobe pontos de vistas e caminhos diferentes percorridos pelos educadores e cientistas. Assim poderemos recomeçar a pensar 0 currículo da Enfermagem.

\section{NURSING CURRICULUM: WITCH WAY TO COMMENCE AND TO RECOMMENCE}

This study relies on the premise that all educational practices are based on presuppositions of philosophic and pedagogical nature, representing the curriculum, the vision of the world, perceived by the school and its professors. The leading question in this research can be formulated as: what is the professors' perception on the guiding concepts of the nursing degree curriculum? 36 professors form 9 nursing schools in the State of São Paulo participated in the research answering enquiries based on the technique of Semantics Differential. The traditional, cognitive, behaviorist, self-realization and social reconstruction concepts guided this analysis. The results of the research expressed the subjects preference for postures of humanistic and social character, demonstrating the orientation for more renovating postures, as well as for more traditional postures, enabling the authors to conclude that there is no predominant guiding conception in the nursing curriculum.

UNITERMS: nursing curriculum, nursing education

\section{EL CURRÍCULO EN LA Y DE LA ENFERMERÍA: POR DONDE COMENZAR Y RECOMENZAR}

Este estudio se apoya en la premisa de que toda práctica educacional se hace fundamentada en presupuestos de naturaleza filosófica y pedagógica, representando el currículo, la visión de mundo percibida por la escuela e sus profesores. La orientación de esta investigación así se coloca: Cual es la percepción del profesor acerca de las concepciones curriculares norteadora del currículo de pre-grado de Enfermería? Parciparon de la investigación 36 profesores de 9 escuelas paulistas de Enfermería que respondieron a la entrevista formulada a partir de la técnica del Diferencial Semántico. Las concepciones educacionales, tradicionalistas, cognitivista, comportamentalistas, de autorrealización y de reconstrucción social, orientaron este análisis. Los resultados de la investigación expresaron las preferencias de los sujetos por posturas educacionales de carácter humanístico y social, demostrando existir orientaciones ora para posturas más 
renovadoras, ora para más tradicionales, caracterizándose por no haber una concepción predominantes en la orientación del currículo. La realidad curricular de la Enfermería demuestra la existencia de un pluralismo de posturas filosóficas y pedagógicas en la orientación de la enseñanza de pre-grado, siendo estas opciones, muchas veces, resultantes de las aspiraciones y de los ideales del propio profesor atribuidos al proceso educacional vigente en la Enfermería.

UNITERMOS: currículum en la enfermería, educación en la enfermería.

\section{REFERÊNCIAS BIBLIOGRÁFICAS}

01. ALMEIDA, M.C.P.; ROCHA, S.M.M.; FREITAS, D.M.V.; MISHIMA, S.; LAUS, E. A formação do enfermeiro frente à reforma sanitária. Cad. Saúde Pública, v. 2, n. 4, p. 505-10, 1986.

02. BICUDO, M.A.V. A filosófica da educação centrada no aluno. In: MARTINS, J.; BICUDO, M.A.V. Estudo sobre o existencialismo, fenomenologia e educação. São Paulo: Ed. Moraes, 1983. p. 45-80.

03. DEWEY, J. Vida e educação (The child and the curriculum and uniterest and effort in education, 1906). 10 ed. Tradução de A. S. Teixeira. São Paulo: Melhoramentos, 1978.

04. DOMINGUES, J. L. Currículo como atividade intencional. In: CAPELLETTI, F.; MASETTO, M. T. (org.). Ensino superior: reflexão e experiência. São Paulo: EDUC/PUC/SP, 1986. p. 43-72.

05. EINER, E.W.; VALLANCE, E. Conflicting conceptions of currículum. Berkeley: MC Cutchan Publ, 1974.

06. FREITAG, B. Escola, Estado e Sociedade. 4. ed. São Paulo: Moraes, 1979.

07. GUIMARÃES, N.S. Relação entre tendências/posturas pedagógicas e procedimentos de avaliação. Tecnol.Educ., Rio de Janeiro, v. 16, n.78/79, p. 47-50, 1987.

08. KNELLER, G.F. Introdução à filosofia da educação. (Introduction to the phylosophy of education). 3. ed. Tradução de Álvaro Cabral. Rio de Janeiro: Zahar, 1971.p.167.

09. MANZOLLI, M.C. Formação do enfermeiro: contribuição da psicologia. São Paulo: Sarvier, 1985.

10. MINISTÉRIO DA EDUCAÇÃO E DO DESPORTO. Conselho Federal de Educação. Parecer 314/94. Currículo mínimo para o curso de enfermagem. Abril, 1994.

11. MIZUKAMI, M.G.N. Ensino: as abordagens do processo. São Paulo: EPU, 1986. 
12. MOREIRA, M. A.; AXT, R. A questão das ênfases curriculares e a formação do professor de ciências. Cad. Catarinense Ensino Física, v. 3, n. 2, p. 66-78, 1986.

13. OSGOOD, C. E.; SUCI, E.; TANNEMBAUM, P. The measurement of meaning. Illinois: University of Illinois Press, 1957.

14. PEREIRA, C.A.A. O diferencial semântico: uma técnica de medida nas ciências humanas. São Paulo: Ática, 1986.

15. PINTO, S.M.P.S. O currículo do curso de graduação em enfermagem. A nova lei do exercício profissional/ as diretrizes da política de saúde atual. In: SESU/MEC/ABEn. Seminário de ensino superior de enfermagem, NorteNordeste. Recife, 1986. p. 36-45.

16. ROGERS, C. Liberdade para aprender. (Freedom to learn). 2. ed. Tradução de E.G.Machado e M.P. Andrade. Belo Horizonte: Inter livros de Minas Gerais, 1972.

17. SAVIANI, D. Escola e democracia. 3. ed. São Paulo: Cortez, 1984.

18. SILVA, T.M.M. A construção do currículo na sala de aula: o professor como pesquisador. São Paulo: EPU, 1990.

19. SKINNER, B.F. Tecnologia do ensino. Tradução de R. Azzi. São Paulo: EPU, EDUSP, 1972.

20. SPERB, D. C. Problemas gerais de currículo. 2. ed. Porto Alegre: Globo, 1975. 21. TABA, H. Elaboración de currículo: teoría y práctica. (Curriculum development: theory and practice) México: Troquel, 1974.

22. YAMAMOTO, M. P.; ROMEU, S.A. Currículo: teoria e prática. In: D'ANTOLA A. (org.). Supervisão e currículo. São Paulo: Pioneira, 1983. 